\title{
XÁC ĐịnH HÀM LƯợNG MỘT SỐ DANG THỦY NGÂN TRONG HẢI SẢN BẰNG PHƯỚNG PHÁP SẮC KÝ LỎNG GHÉP NỐl KHỐI PHỔ PLASMA CAO TẦN CẢM ỨNG (LC-ICP-MS)
}

\author{
Phạm Công Hiếu ${ }^{1,2}$, Đinh Viết Chiến ${ }^{2 *}$, Nguyễn Văn Ri ${ }^{1}$ \\ Nguyễn Thị Ánh Hường ${ }^{1}$, Lê Thị Hồng Hảo ${ }^{1,2}$, Nguyễn Thị Minh Lọi ${ }^{3}$ \\ ${ }^{1}$ Khoa Hóa hoc - Truờng Đại học Khoa học Tụ̂ nhiên - Đại học Quốc gia Hà Nội \\ ${ }^{2}$ Viện Kiểm nghiệm An toàn vệ sinh thực phẩm Quốc gia \\ ${ }^{3}$ Trường Đại hoc Quảng Bình
}

(Ngày đến tòa soạn: 10/10/2019; Ngày sửa bài sau phản biện: 18/11/2019;

Ngày chấp nhận đăng: 28/11/2019)

\section{Tóm tắt}

Phương pháp sắc ký lỏng ghép nối khối phổ plasma cao tần cảm ứng (LC-ICP-MS) đã được nghiên cứu ứng dụng nhằm xác định đồng thời hàm lượng của ba dạng thủy ngân (thủy ngân, methyl thủy ngân và ethyl thủy ngân) trong mẫu hải sản. Các thông số quan trọng được tối ưu như ảnh hưởng của dung môi hữu cơ, tốc độ dòng pha động, nồng độ 2-mercaptoethanol, nhiệt độ và thời gian chiết. Phương pháp đã được đánh giá với các thông số giới hạn phát hiện, giới hạn định lượng, độ lặp lại, hiệu suất thu hồi phù hợp với tiêu chuẩn AOAC. Phương pháp cũng được xác nhận độ chính xác dựa trên phân tích mẫu chuẩn chứng nhận DORM-4 và áp dụng để phân tích đồng thời hàm lượng ba dạng thủy ngân trong 30 mẫu hải sản. Kết quả cho thấy hàm lượng các dạng thủy ngân trong các mẫu phân tích đều thấp hơn mức cho phép theo quy định của QCVN 8-2:2011/BYT.

Tù khóa: Các dạng thủy ngân, Hg, methyl thủy ngân, ethyl thủy ngân, hải sản, $L C-I C P-M S$.

\section{MỞ ĐÀ̀}

Thủy ngân là một nguyên tố kim loại ở dạng lỏng, chiếm tỉ lệ rất nhỏ trong vỏ trái đất, nhưng lại được sử dụng khá rộng rãi trong cuộc sống, từ lĩnh vực y học (nhiệt kế, trám men răng, thuốc,...) cho đến nông nghiệp (thuốc trừ sâu, diệt cỏ, diệt nấm,...) và đặc biệt là trong các ngành công nghiệp như: luyện kim, sản xuất xi măng, khai thác khoáng vàng,... Từ đó, thủy ngân dễ dàng phát tán vào môi trường thủy sinh, sau đó được tích lũy và chuyển hóa bởi vi khuẩn để tạo thành các hợp chất thủy ngân hữu cơ, như ethyl thủy ngân, methyl thủy ngân với độc tính cao [6, 14$]$. Các hợp chất thủy ngân tích tụ trong các loài hải sản có thể gây ảnh hưởng đến sức khỏe con người thông qua chuỗi thức ăn. Khi xâm nhập vào cơ thể con người, thủy ngân sẽ tích lũy trong thời gian dài và rất khó bị loại bỏ $[6,11,12,14]$. Do vậy, việc xác định hàm lượng một số dạng thủy ngân như thủy ngân, methyl thủy ngân và ethyl thủy ngân trong hải sản là cần thiết, nhằm cảnh báo và ngăn ngừa mối nguy ô nhiễm thủy ngân cho người tiêu dùng.

Để xác định riêng rẽ và đồng thời các dạng thủy ngân, một số phương pháp thường được sử dụng như: quang phổ hấp thụ nguyên tử kết hợp kỹ thuật hóa hơi lạnh $(\mathrm{CV}-\mathrm{AAS})^{2}[5,7,9]$, sắc ký khí $[4,12]$, sắc ký lỏng hiệu năng cao ghép nối quang phổ hấp thụ nguyên tử (HPLCAAS) hoặc khối phổ plasma cao tần cảm ứng (LC-ICP-MS),...[2, 7, 8, 10, 11, 13]. Với ưu điểm là độ nhạy cao, độ ổn định tốt, thời gian phân tích phù hợp, quy trình xử lý mẫu không phức tạp, 
trong nghiên cứu này, phương pháp sắc ký lỏng phép nối khối phổ plasma cao tần cảm ứng (LC-ICP-MS) được lựa chọn nhằm xác định đồng thời ba dạng: thủy ngân, methyl thủy ngân và ethyl thủy ngân trong một số mẫu hải sản.

\section{HÓA CHẤT VÀ THIẾT BI}

\subsection{Hóa chất}

Tất cả các hóa chất, thuốc thử sử dụng trong nghiên cứu này đều thuộc loại tinh khiết phân tích: các chất chuẩn $\mathrm{Hg} 1000$ ppm (Merck), methyl thủy ngân $(\mathrm{MeHg})>$ 99,8\%, (SigmaAldrich), ethyl thủy ngân $(\mathrm{EtHg})>99,9 \%$ (TRC), mẫu chuẩn chứng nhận DORM-4 (Canada), các hóa chất khác: HCl 37\% (Merck), methanol (MeOH), isopropanol (IsP), 2-mercaptoethanol $(2-\mathrm{ME})>$ 99,9 (Sigma), muối amonium acetate > 99\% (Merck), khí argon có độ tinh khiết 99,999\% (Messer), nước deion. Ngoài ra, các dung dịch chuẩn hóa thiết bị của hãng Perkin Elmer và dung dịch làm mát (cho Chiller) cũng được sử dụng.

\subsection{Thiết bị}

Thiết bị sắc ký lỏng phép nối khối phổ plasma cao tần cảm ứng LC-ICP-MS (Model NexION 350X) của hãng Perkin Elmer có trang bị hệ thống buồng động học (hình 1) được sử dụng trong nghiên cứu này.

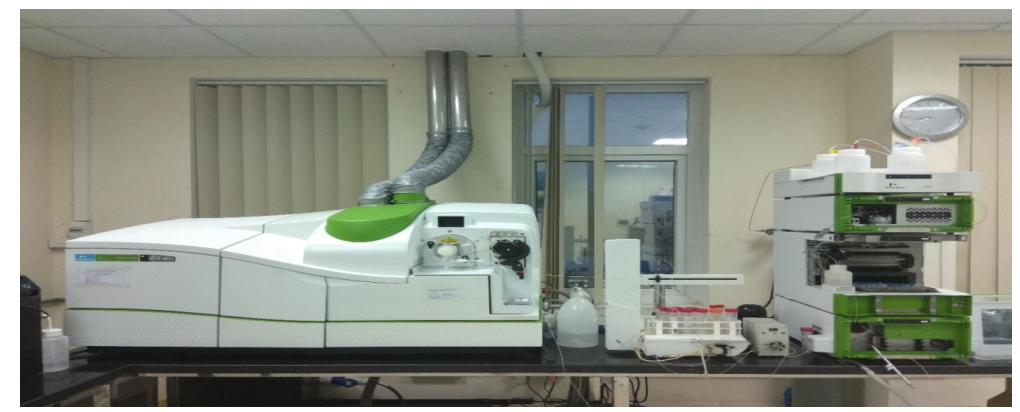

Hình 1. Hệ thiết bị LC-ICP-MS sủ dụng trong nghiên cúu

\section{KẾT QUẢ VÀ BÀN LUẬN}

\subsection{Lựa chọn, tối ưu các điều kiện phân tích trên ICP-MS}

Trong nghiên cứu này, số khối $\mathrm{Hg}^{202}$ được lựa chọn, ít bị ảnh hưởng bởi sự trùng khối và cũng là đồng vị phổ biến nhất của thủy ngân trong tự nhiên $(29,86 \%)$, có thể phân tích bằng chế độ chuẩn (standard mode). Các thông số khác có ảnh hưởng đến độ chính xác, độ nhạy, độ ổn định của phép phân tích như công suất RF, lưu lượng khí mang, độ sâu plasma, thế thấu kính ion,... được tối ưu tự động trên hệ thống (sử dụng phần mềm và các dung dịch chuẩn hóa thiết bị được hãng Perkin Elmer cung cấp). Kết quả được thể hiện như trong bảng 1 .

Bảng 1. Các thông số tối ưu tự động của thiết bị ICP-MS

\begin{tabular}{|c|c|c|c|}
\hline Thông số & Giá trị đự̣c chọn & Thông số & Giá trị đự̣c chọn \\
\hline Công suất $R F$ & $1250 \mathrm{~W}$ & Số lần quét khối & 20 lần \\
\hline Lưu luọng khí & $0,8 \mathrm{~mL} /$ phút & Số lần đo lặp & 3 lần \\
\hline $\begin{array}{l}\text { Luu luọng khí tạo } \\
\text { plasma }\end{array}$ & 19,0 L/phút & Độ sâu plasma & Chỉnh ở tối ưu \\
\hline Thế xung cấp & $1000 \mathrm{~V}$ & Chế độ đo & Chuẩn (Standard) \\
\hline $\begin{array}{l}\text { Thế quét phổ truòng } \\
\text { tứ cụcc }\end{array}$ & Tự động theo $\mathrm{m} / \mathrm{Z}$ & Các thông số khác & Tự động (Auto) \\
\hline
\end{tabular}

34 | Tạp chí KIỂM NGHIỆM VÀ AN TOÀN THỰC PHẨM (Số 4-2019) 
Các thông số ảnh hưởng (bảng 1) được tối ưu đồng thời sao cho vừa đạt được tín hiệu cao nhất của chất phân tích (thủy ngân), vừa giảm được ảnh hưởng nhiễu nền. Việc tối ưu được thực hiện bằng dung dịch chuẩn hóa thiết bị của hãng có chứa các nguyên tố có số khối từ nhỏ như Be (9), đến số khối trung bình In (115) và số khối lớn như U (238), để có thể đại diện cho các nguyên tố nghiên cứu. Sau khi thực hiện tối ưu tự động, các thông số cần phải kiểm tra để đạt được các giá trị yêu cầu tương ứng. Trong đó, độ nhạy của thiết bị chủ yếu dựa trên tính đáp ứng về cường độ của nguyên tố Indium, tî̉ lệ $\mathrm{CeO} / \mathrm{Ce}$ và $\mathrm{Ce}^{++} / \mathrm{Ce}$. Cường độ thực tế của các thông số sau mỗi lần kiểm tra hàng ngày có thể thay đổi, nhưng vẫn phải đạt được theo tiêu chuẩn kiểm tra của hãng để đảm bảo độ ổn định, độ nhạy của thiết bị.

\subsection{Khảo sát, tối ưu các điều kiện phân tách và định lượng methyl thủy ngân $(\mathrm{MeHg})$}

Những yếu tố quan trọng ảnh hưởng đến quá trình tách trên HPLC (về thời gian lưu, độ phân giải, cường độ tín hiệu chất phân tích) như: ảnh hưởng của dung môi hữu cơ (loại và nồng độ), tốc độ dòng pha động và nồng độ chất tạo cặp (2-ME). Các điều kiện LC khác bao gồm: cột sắc ký $\mathrm{C} 18\left(5 \mu \mathrm{m}, 150 \mathrm{x}\right.$ 4,6 mm), pha động chứa $\mathrm{CH}_{3} \mathrm{COONH}_{4} 20 \mathrm{mM}$ được giữ cố định.

\subsubsection{Khảo sát ảnh hưởng của dung môi hũu co}

Các dung môi được lựa chọn để khảo sát trong nghiên cứu này gồm: methanol $(\mathrm{MeOH})$ và isopropanol (IsP) với nồng độ $1 \div 5 \%$ (trong phép đo ICP-MS, nồng độ dung môi hữu cơ được khuyến cáo $<5 \%$ để đảm bảo nguồn ICP hoạt động hiệu quả). Tiến hành nghiên cứu ảnh hưởng của dung môi hữu cơ đến thời gian lưu và độ phân giải của hai chất có độ phân cực lớn hơn (thời gian lưu ngắn hơn khi sử dụng cột $\mathrm{C} 18$ ) là $\mathrm{Hg}^{2+}$ và $\mathrm{MeHg}$.

Trong pha động sử dụng $\mathrm{MeOH}$, thời gian lưu đã được rút ngắn hơn so với khi không có mặt dung môi hữu cơ nhưng tổng thời gian phân tích còn khá dài. Trong khi đó, khi sử dụng isopropanol vẫn cho độ phân giải tốt giữa các chất phân tích với thời gian phân tích ngắn và tín hiệu các chất phân tích lớn hơn trong trường hợp dùng $\mathrm{MeOH}$ [2]. Do đó, dung môi isopropanol được lựa chọn.

Kết quả khảo sát nồng độ của isopropanol dựa trên các thông số về tín hiệu đo, thời gian lưu và độ phân giải, nồng độ tối ưu của isopropanol trong khoảng $1 \div 5 \%$ cho thấy, tại nồng độ $4 \%$ cho tín hiệu các chất được rửa giải hoàn toàn ra khỏi cột trong 20 phút, đồng thời các chất có độ phân giải tốt, đáp ứng yêu cầu phân tích định lượng. Vì vậy nồng độ isopropanol $4 \%$ được giữ cố định cho các nghiên cứu tiếp theo.

\subsubsection{Khảo sát tốc độ dòng pha động}

Tốc độ pha động phải đảm bảo không quá nhỏ giúp giảm thời gian phân tích nhưng không nên vượt quá $1 \mathrm{~mL} /$ phút để giữ ổn định áp suất cho cột và hệ thống bơm. Do đó, tốc độ dòng được khảo sát thay đổi từ $0,7-1,0 \mathrm{~mL} /$ phút (với bước nhảy của mỗi khảo sát là $0,1 \mathrm{~mL} /$ phút). Kết quả cho thấy, khi tốc độ dòng được thay đổi từ $0,7-1,0 \mathrm{~mL} /$ phút, thời gian lưu được rút ngắn qua từng khảo sát. Tuy nhiên, để đảm bảo tính ổn định của cột và hệ thiết bị, tốc độ dòng là $0,9 \mathrm{~mL} /$ phút (hình 2) được lựa chọn cho các khảo sát tiếp theo.

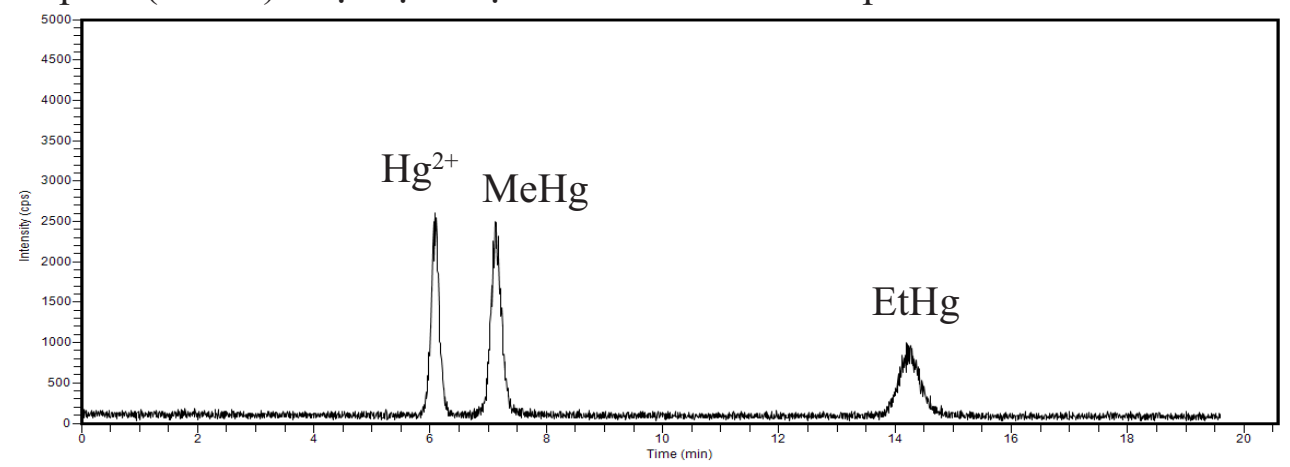

Hinh 2. Sắc ký đồ phân tích hỗn hợp 3 chất nồng độ 10 ppb với tốc độ dòng $0,9 \mathrm{ml} /$ phút 


\subsubsection{Khảo sát nồng độ chất tạo cặp 2-ME trong thành phần pha động}

Sau khi tối ưu được thành phần dung môi hữu cơ và tốc độ dòng, một yếu tố khác trong thành phần pha động cũng rất quan trọng và cần được nghiên cứu là chất tạo cặp 2-ME. Các dạng thủy ngân là những hợp chất có độ phân cực cao, ái lực với cột $\mathrm{C} 18$ nhỏ, do đó cần sử dụng thêm chất tạo cặp trong pha động giúp tăng khả năng tương tác của từng chất phân tích với cột pha đảo, nhờ đó các chất được tách hiệu quả trên cột. Các nồng độ khác nhau của 2-ME được khảo sát gồm: $0,05 \%, 0,10 \%, 0,20 \%$. Kết quả cho thấy, khi nồng độ chất tạo cặp 2-ME tăng lên, tín hiệu chất phân tích cũng như độ phân giải của các chất phân tích tăng nhưng không nhiều. Do 2-ME là dung môi có khả năng bay hơi mạnh, mùi khó chịu, có thể ảnh hưởng tới sức khỏe người sử dụng, do đó, nồng độ của $2-\mathrm{ME} 0,10 \%$ được lựa chọn phù hợp cho các khảo sát tiếp theo.

\subsection{Khảo sát điều kiện xử lý mẫu}

Các điều kiện cần khảo sát để đạt được hiệu quả xử lý mẫu tốt nhất trong môi trường acid chiết mẫu là $\mathrm{HCl}$ có nồng độ $1 \mathrm{~mol} / \mathrm{L}[2,9,13]$ gồm: nhiệt độ và thời gian chiết, tỷ lệ $2-\mathrm{ME}$ trong dung môi chiết.

\subsubsection{Khảo sát nhiệt độ chiết}

Nhiệt độ là yếu tố ảnh hưởng trực tiếp tới quá trình xử lý mẫu, trong quá trình chiết nhiệt độ quá thấp sẽ làm giảm hiệu suất chiết, chất phân tích không được tách hoàn toàn ra khỏi nền mẫu, gây sai số cho phương pháp. Tuy nhiên, thủy ngân là kim loại dễ bay hơi và các dạng thủy ngân hữu cơ cũng kém bền, có thể chuyển về dạng vô cơ ở nhiệt độ cao, do đó khoảng nhiệt độ khảo sát không nên quá cao. Trong nghiên cứu này, nhiệt độ khảo sát thay đổi trong khoảng 50 $\div 80^{\circ} \mathrm{C}$, với giá trị bước khảo sát là $10^{\circ} \mathrm{C}$. Kết quả khảo sát cho thấy, hàm lượng của chất phân tích tăng lên khi nhiệt độ tăng từ $50^{\circ} \mathrm{C}$ đến $60^{\circ} \mathrm{C}$. Tuy nhiên khi nhiệt độ tăng lên $70^{\circ} \mathrm{C}, 80^{\circ} \mathrm{C}$ thì hàm lượng $\mathrm{MeHg}$ có xu hướng giảm đáng kể. Do đó, nhiệt độ chiết mẫu $60^{\circ} \mathrm{C}$ được lựa chọn.

\subsubsection{Anh hương của thời gian chiết}

Thời gian chiết cũng là thông số quan trọng ảnh hưởng đến hiệu suất chiết. Các thời gian chiết được lựa chọn khảo sát trong nghiên cứu này là $20,30,40,50$ và 60 phút. Kết quả cho thấy, khi nhiệt độ tăng từ 20 đến 40 phút, hàm lượng $\mathrm{MeHg}$ tăng và đạt mức tối đa tại 40 phút sau đó không có sự thay đổi đáng kể khi tăng thời gian chiết. Do đó, thời gian chiết 40 phút được lựa chọn là điều kiện chiết tối ưu cho quy trình xử lý mẫu.

\subsubsection{Anh huởng của 2-Mercaptoethanol}

Trong quá trình chiết mẫu, dung môi được chọn có chứa mercaptoethanol (2-ME), hợp chất có ảnh hưởng đáng kể đến hiệu quả chiết. Do đó, nồng độ của 2-ME sử dụng trong quá trình chiết đã được nghiên cứu khảo sát và kết quả thể hiện trong hình 3.

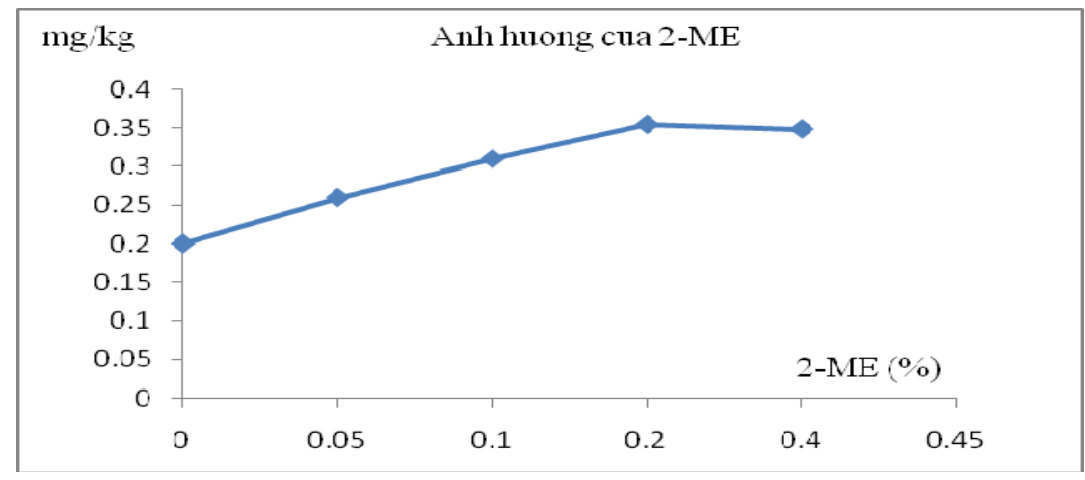

Hình 3. Anh hưởng của nồng độ 2-Mercaptoethanol trong quá trình chiết mẫu 
Kết quả trong hình 4 cho thấy, mặc dù các giá trị thu được của chất phân tích (đại diện là $\mathrm{MeHg}$ ) tăng nhanh khi tăng nồng độ $2-\mathrm{ME}$ từ 0 đến $0,2 \%$, tuy nhiên không có thay đổi đáng kể của $\mathrm{MeHg}$ khi nồng độ $2-\mathrm{ME}$ thay đổi từ 0,2 đến $0,4 \%$. Do đó, nồng độ $2-\mathrm{ME} 0,2 \%$ được lựa chọn.

Từ các kết quả khảo sát, quy trình xử lý mẫu đối với với nền mẫu hải sản được thể hiện trong hình 4.

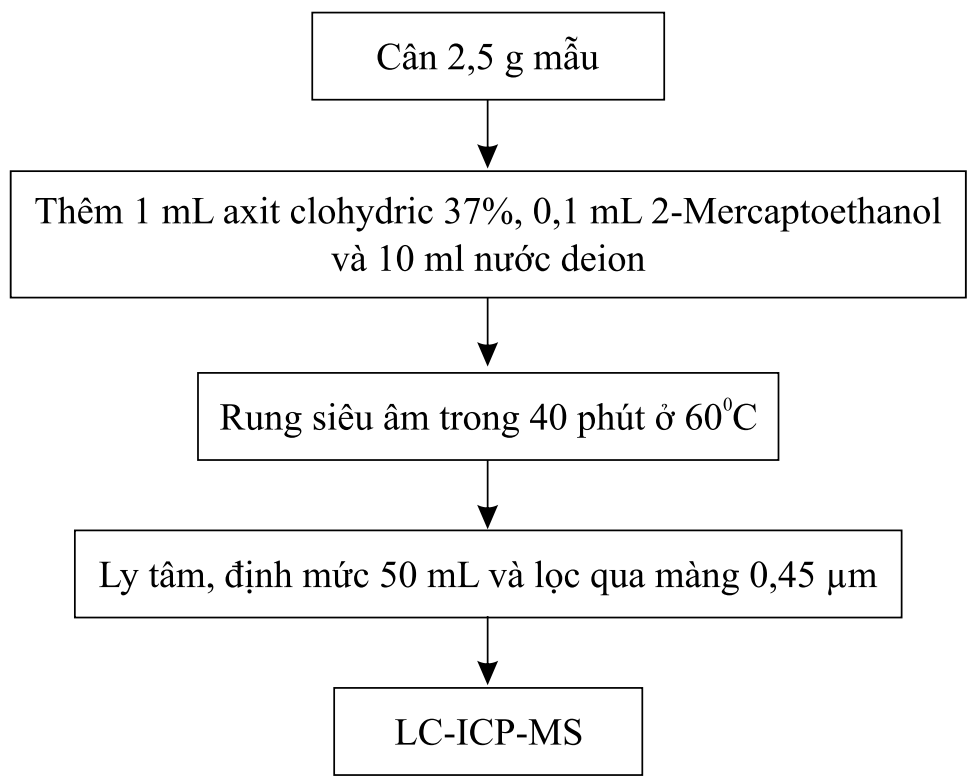

Hình 4. Quy trình phân tích hàm lương ba dạng thủy ngân trong mẫu hải sản bằng $L C-I C P-M S$

Quy trình này sẽ được sử dụng để thẩm định phương pháp và áp dụng phân tích mẫu thực tế.

\section{4. Đánh giá phương pháp phân tích}

Việc đánh giá phương pháp được thực hiện trên cơ sở các điều kiện tối ưu thu được, gồm: xây dựng đường chuẩn phân tích ba dạng thủy ngân $\left(\mathrm{Hg}^{2+}, \mathrm{MeHg}, \mathrm{EtHg}\right)$, xác định giới hạn phát hiện (LOD), giới hạn định lượng (LOQ), độ chụm (thông qua độ lặp, độ tái lặp), độ đúng (thông qua độ thu hồi) và phân tích mẫu chuẩn CRM.

Đường chuẩn xác định ba dạng thủy ngân bằng phương pháp LC-ICP-MS được xây dựng trong khoảng nồng độ $1 \div 20 \mathrm{ng} / \mathrm{mL}$. Kết quả phương trình đường chuẩn, giới hạn phát hiện của phương pháp (MDL) trên nền mẫu cá (khối lượng cân mẫu 2,5 gam và thể tích định mức 50 $\mathrm{mL}$ ) được thể hiện trong bảng 2 .

Bảng 2. Đuờng chuẩn phân tích các dạng thủy ngân và giới hạn phát hiện của phuơng pháp

\begin{tabular}{|c|c|c|c|}
\hline Chất phân tích & $\begin{array}{c}\text { Phuơng trình đưòng chuẩn } \\
\boldsymbol{Y}=\boldsymbol{a}+\boldsymbol{b x}\end{array}$ & $\begin{array}{c}\text { Hệ số } \\
\text { tuoong quan }\end{array}$ & $\begin{array}{c}\boldsymbol{M D L} \\
(\boldsymbol{\mu g} / \boldsymbol{k g})\end{array}$ \\
\hline $\boldsymbol{M e H g}$ & $\mathrm{y}=-1,970+3007 \mathrm{x}$ & 1,000 & 10 \\
\hline $\boldsymbol{E} t \boldsymbol{H g}$ & $\mathrm{y}=195,7+2625 \mathrm{x}$ & 0,999 & 24 \\
\hline $\boldsymbol{H g}^{\mathbf{2 +}}$ & $\mathrm{y}=0,068+2847 \mathrm{x}$ & 1,000 & 10 \\
\hline
\end{tabular}

Độ lặp lại được đánh giá trên nền mẫu cá với $\mathrm{n}=6$ ở mức hàm lượng $1,0 \mathrm{mg} / \mathrm{kg}$. Kết quả độ lệch chuẩn tương đối (RSD) cho các giá trị với cả ba dạng thủy ngân đều nằm trong khoảng $4,03 \div 5,52 \%$. Độ tái lặp được thực hiện ở hai ngày phân tích và người thực hiện khác nhau với 
$\mathrm{n}=4$ cho kết quả $\mathrm{RSD}_{\mathrm{r}}$ trong khoảng $5,54 \div 8,63 \%$. Độ thu hồi ở mức thêm chuẩn $0,2 \mathrm{mg} / \mathrm{kg}$ $(\mathrm{n}=6)$ trên nền mẫu trẳng cho kết quả tương ứng với $\mathrm{MeHg}, \mathrm{EtHg}$ và $\mathrm{Hg}$ là $96,35 \%, 93,10 \%$ và $95,17 \%$. Các kết quả này đều nằm trong giới hạn cho phép của $\mathrm{AOAC}$ ở các mức hàm lượng khảo sát tương ứng [3]. Kết quả khảo sát cho thấy phương pháp có chụm và độ chính xác tốt, phù hợp để xác định hàm lượng ba dạng thủy ngân trong mẫu hải sản.

Để kiểm chứng phương pháp, mẫu chuẩn DORM-4 của các kim loại $(\mathrm{Pb}, \mathrm{Cd}, \mathrm{As}, \mathrm{MeHg}$...) trong nền mẫu cá đã được phân tích. Mẫu được Hội đồng nghiên cứu Quốc Gia Canada (NRC-CNRC) sản xuất và được chứng nhận bởi các phòng thí nghiệm uy tín trên thế giới. Kết quả phân tích được thể hiện trong bảng 3 .

Bảng 3. Kết quả phân tích mẫu chuẩn (CRM) DORM-4

\begin{tabular}{|c|c|c|c|}
\hline \multicolumn{2}{|c|}{ DORM-4 } & \multicolumn{2}{c|}{ Hàm luọng phân tích (mg/kg) } \\
\hline MeHg & Hg tổng số & MeHg & Hg $^{\mathbf{2}^{+}}$ \\
\hline $0,355 \pm 0,028$ & $0,412 \pm 0,036$ & $0,342 \pm 0,037$ & $0,057 \pm 0,008$ \\
\hline
\end{tabular}

Kết quả phân tích mẫu chuẩn DORM-4 cho thấy hàm lượng MeHg đạt yêu cầu, chứng tỏ phương pháp có độ tin cậy tốt, hoàn toàn phù hợp để phân tích các dạng thủy ngân trên nền mẫu hải sản.

\subsection{Phân tích mẫu thực tế}

Các mẫu lựa chọn để phân tích được lấy ngẫu nhiên trên địa bàn Hà Nội gồm hơn 30 mẫu với 12 loại thủy hải sản. Các mẫu nghiên cứu có cả loài ăn thịt có nguy cơ tích lũy hàm lượng thủy ngân cao (cá mút đá, cá ngừ,...) và loại ăn thực vật và vi sinh vật phù du nhỏ có mức độ tích lũy thủy ngân thấp hơn (cá trắm, cá chép,...). Hàm lượng trung bình của ba dạng thủy ngân trong các mẫu khảo sát và một số sắc đồ minh họa được thể hiện trong bảng 4 và hình 5 .

Bảng 4. Kết quả phân tích hàm lượng ba dạng thủy ngân trong một số mẫu hải sản

\begin{tabular}{|c|c|c|c|}
\hline Loài/số lự̣ng (n) & $\mathrm{MeHg}(\mathrm{mg} / \mathrm{kg})$ & EtHg $(\mathrm{mg} / \mathrm{kg})$ & $\mathrm{Hg}^{2+}(\mathrm{mg} / \mathrm{kg})$ \\
\hline Cá mút đá $(n=3)$ & $0,61 \pm 0,07$ & - & $0,052 \pm 0,08$ \\
\hline Mục nang $(n=3)$ & $0,10 \pm 0,011$ & - & $<0,03$ \\
\hline Cá ngù̀ $(n=2)$ & $0,23 \pm 0,025$ & - & - \\
\hline Cá trúng $(n=3)$ & $<0,03$ & - & - \\
\hline Cá hồi $(n=3)$ & $<0,03$ & - & - \\
\hline Cá thu $(n=4)$ & $<0,03$ & - & - \\
\hline Cá basa $(n=3)$ & $<0,03$ & - & - \\
\hline Cá hồng (n=2) & $<0,03$ & - & $<0,03$ \\
\hline Cá nục (n=3) & $<0,03$ & - & - \\
\hline Cá trắm cỏ $(n=2)$ & - & - & - \\
\hline Cá chép $(n=1)$ & - & - & - \\
\hline Tôm càng xanh $(n=1)$ & - & - & - \\
\hline
\end{tabular}

Ghi chú (-) : Mẫu có hàm luợng chất phân tích nhỏ hơn giới hạn phát hiện của phuoong pháp 


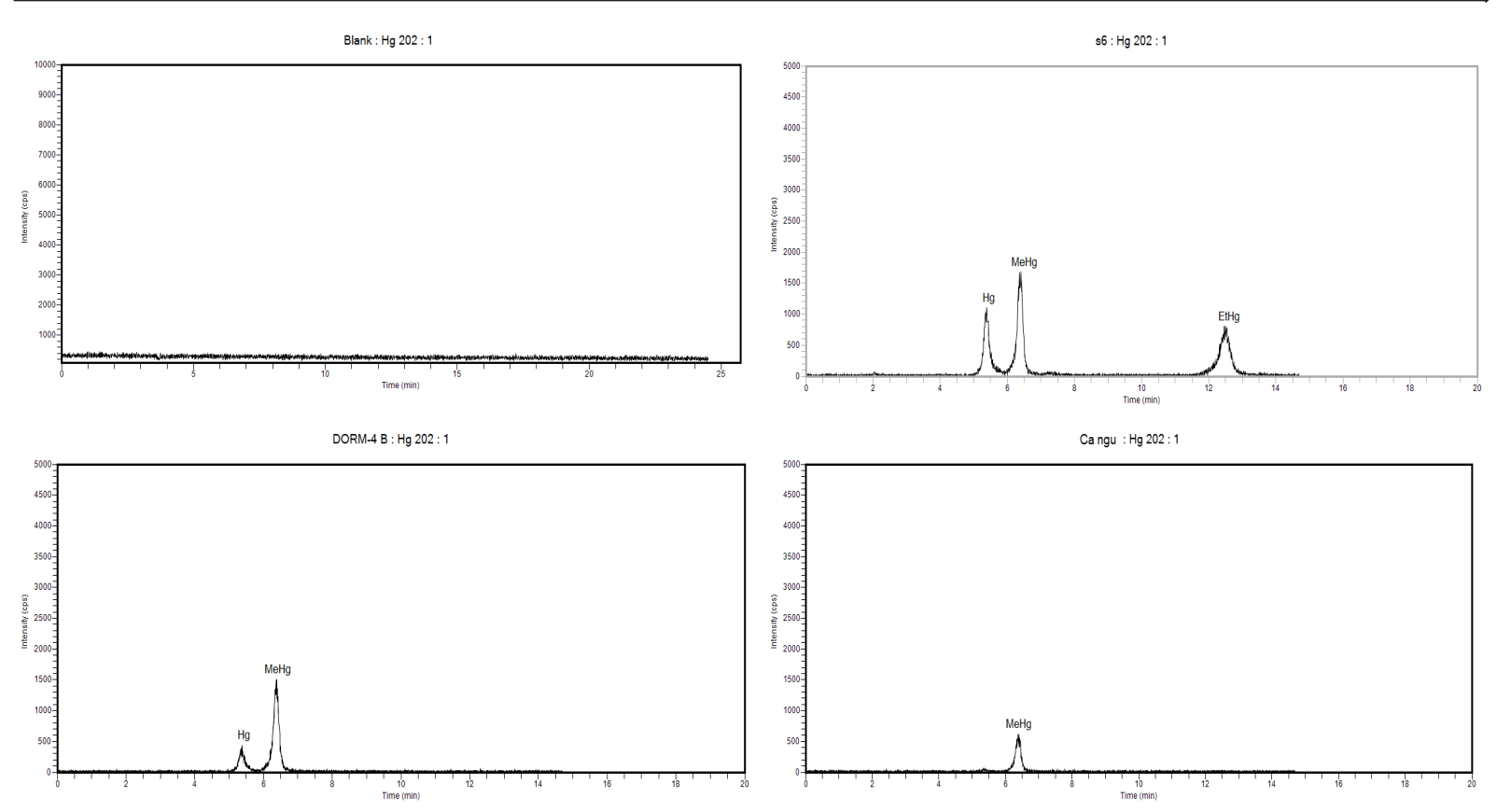

Hình 5. Sắc đồ phân tích dạng thủy ngân trong mãu hải sản

Từ kết quả trong bảng 4 cho thấy, tất cả các mẫu đều không phát hiện hàm lượng EtHg, trong khi hàm lượng $\mathrm{MeHg}$ chiếm tới khoảng $90 \%$ so với hàm lượng thủy ngân tổng số trong các mẫu hải sản có phát hiện. Các loài ăn thịt có hàm lượng methyl thủy ngân cao hơn các loài chủ yếu ăn thực vật và sinh vật phù du nhỏ là phù hợp với quy luật tích lũy thủy ngân trong tự nhiên. Tuy nhiên tất cả các mẫu đều có hàm lượng $\mathrm{MeHg}$ nằm trong giới hạn cho phép của Bộ Y tế (QCVN 8-2: 2011/BYT): $\leq 1 \mathrm{mg} / \mathrm{kg}$ đối với cá thịt, $\leq 0,5 \mathrm{mg} / \mathrm{kg}$ với tất cả các loài cá (không bao gồm cá cho thịt) [1]. Như vậy, bước đầu có thể nhận thấy mức độ ô nhiễm thủy ngân trong hải sản ở nước ta vẫn trong mức an toàn, tuy nhiên, cần có những nghiên cứu sâu hơn nhằm có kết quả toàn diện hơn để ngăn ngừa nguy cơ ô nhiễm thủy ngân đối với người tiêu dùng.

\section{KẾT LUẬN}

Trong nghiên cứu này, các thông số ảnh hưởng đến việc phân tách bằng LC-ICP-MS và quy trình xử lí mẫu đã được tối ưu nhằm xác định đồng thời ba dạng thủy ngân $\left(\mathrm{Hg}^{2+}, \mathrm{MeHg}\right.$, EtHg) trong một số mẫu hải sản. Phương pháp đã được thẩm định cho giới hạn phát hiện trong khoảng $10 \div 24$, với độ lặp lại Phương pháp được áp dụng để phân tích 12 loài với hơn 30 mẫu thủy hải sản và đã phát hiện hàm lượng $\mathrm{Hg}, \mathrm{MeHg}$ trong một số mẫu nhưng vẫn nằm trong ngưỡng an toàn theo QCVN 8-2:2011/BYT.

\section{TÀI LIỆU THAM KHẢO}

1. QCVN 8-2:2011/BYT, "Quy chuẩn kỹ thuật quốc gia đối với giới hạn ô nhiễm kim loại nặng trong thực phẩm".

2. Phạm Công Hiếu, Chu Văn kết, Đinh Viết Chiến, Lê Đức Dũng, Nguyễn Văn Ri, Nguyễn Thị Ánh Hường, Lê Thị Hồng Hảo (2018), "Xác định methyl thủy ngân trong mẫu thủy sản bằng phương pháp sắc ký lỏng ghép nối khối phố plasma cao tần cảm ứng (LC-ICP/MS)", Tạp chí phân tích Hóa, Lý và Sinh học, 5 (23), 173-176.

3. AOAC (2012), "Appendix F: Guidelines for standard method performance requirements", AOAC official methods of Analysis, 9. 
4. A.M. Caricchia, G. Minervini, P. Soldati, S. Chiavarini, C. Ubaldi, R. Morabito (1997), "GC-ECD determination of methylmercury in sediment samples using a SPB-608 capillary column after alkaline digestion”, Microchem J., 55 (1), 44 - 55.

5. A.Q.Shaha, T.G Kazia,*, J.A. Baiga,1, H.IAfridia, M.B Arainb. (2012). "Simultaneously determination of methyl and inorganic mercury in fish species by cold vapour generation atomic absorption spectrometry“, Food Chemistry, 134, 2345 - 2349.

6. Council, N. R. (2000). "Toxicological effects of Methylmercury.", National Academies Press, Washington D.C.

7. Corrado Sarzanini, Giovanni Sacchero, Maurizio Aceto, Ornella Abollino, Edoardo Mentasti (1992), "Simultaneous determination of methyl-, ethyl-, phenyl- and inorganic mercury by cold vapour atomic absorption spectrometry with on-line chromatographic separation", Journal of Chromatography A, (626), Issue 1, 151 - 157.

8. J. Retka, A. M., D. Karmasz (2011). "Determination of Cu, Ni, Zn, Pb, Cd by ICP-MS and Hg by AAS in plant samples", Accumulation in foods and crops, 15th ICHMET, 373 - 375.

9. Koplík R., Klimešová I., Mališová K., Oto Mestek (2014), “Determination of Mercury Species in Foodstuffs using LC-ICP/MS: the Applicability and Limitations of the Method", Czech Journal of Food Sciences, 3 (3), 249 - 259

10. Sang Hak Lee, Jung Ki shu (2005), "Determination of mercury in tuna fish tissue using isotope dilution-inductively coupled plasma mass spectrometry", Microchemical Journal, $80,233-236$.

11. S. Mishra, R. M. T., S. Bhalke, V.K Shukla, V.D Puranik (2005), "Determination of Methyl mercury and mercury (II) in a marine ecosystem using solid-phase microextraction gas chromatography-mass spectrometry", Analytic Chimica. Acta, (551), 192 - 198.

12. Walter Holak (1982), "Determination of Methylmercury in Fish by High-performance Liquid Chromatography”, Analyst, Vol. (107), 1457 - 1461.

13. Hight, S. C., and Cheng, J. (2006), "Determination of Methylmercury and Estimation of Total Mercury in Seafood Using High Performance Liquid Chromatography (HPLC) and Inductively Coupled Plasma-Mass Spectrometry (ICP-MS): Method Development and Validation", Anal. Chim. Acta, (567), 160 - 172.

14. WHO (1989b), "Evaluation of certain food additives and contaminants", Thirty-thirt re port of the Point FAO/WHO Expert Committee on Food Additives, Gevena, World Health Organization (WHO Technical Report Series 776).

\section{Summary}

\section{DETERMINATION OF MERCURY SPECIES IN SEAFOOD BY LIQUID}

\section{CHROM TOGRAPHY - INDUCTIVELY COUPLED PLASMA MASS SPECTROMETRY (LC-ICP-MS)}

\section{Pham Cong Hieu ${ }^{1,2}$, Dinh Viet Chien ${ }^{2 *}$, Nguyen Van $\mathrm{Ri}^{1}$, Nguyen Thi Anh Huong ${ }^{1}$ Le Thi Hong Hao ${ }^{1,2}$, Nguyen Thi Minh Loi ${ }^{3}$}

${ }^{1}$ Faculty of Chemistry, VNU University of Science, Vietnam National University-Hanoi

${ }^{2}$ National Institute for Food Control, Vietnam

${ }^{3}$ Quang Binh University

Liquid chromatography hyphenated with inductively coupled plasma mass spectrometry (LC-ICP-MS) was investigated to simultaneously determine three mercury species (mercury, 
methyl mercury and ethyl mercury) in seafood samples. Important parameters such as organic solvents, flow rate of the mobile phase, 2-mercaptoethanol concentration, extraction time and temperature were optimized. The method was validated in term of the limit of detection, limit of quantitation, repeatability, and recovery meeting the AOAC performance requirements. The method has also been validated based on the analysis of certified standard samples DORM-4, then applied to determine three mercury species in 30 seafood samples. Results showed that the content of mercury species was below the maximum limit according to the QCVN 8-2 : 2011/BYT.

Keywords: Mercury species, Hg, methyl mercury, ethyl mercury, sea food, LC-ICP-MS. 